\title{
Espermiogênese em Eupemphix nattereri (Anura, Leiuperidae): aspectos ultra-estruturais
}

\author{
Rodrigo Zieri ${ }^{1}$, Sebastião R. Taboga ${ }^{2} \&$ Classius de Oliveira
}

\author{
1 Universidade Estadual Paulista (UNESP), Campus de São José do Rio Preto. Instituto de Biociências, Letras e Ciências Exatas, Programa \\ de Pós-graduação em Biologia Animal, R. Cristóvão Colombo 2265, Jd. Nazareth, 15054-000 São José do Rio Preto, SP, Brasil. \\ (rodrigozieri@yahoo.com.br) \\ 2. Universidade Estadual Paulista (UNESP), Campus de São José do Rio Preto, São Paulo, Brasil. Departamento de Biologia, R. Cristóvão \\ Colombo 2265, Jd. Nazareth, 15054-000. (classius@ibilce.com.br)
}

\begin{abstract}
Spermiogenesis in Eupemphix nattereri (Anura, Leiuperidae): ultrastructural aspects. Spermatozoon maturation involves an extense and complex process beginning with proliferation and differentiation of spermatogonia, passing through meiosis, and ending with spermiogenesis. The later event involves morphological and biochemical changes in order to transform spermatids into spermatozoa. Ultrastructural aspects of the spermiogenesis and testicular spermatozoa of the anuran Eupemphix nattereri (Steindachner, 1863) were analyzed by transmission electron microscopy. Spermiogenesis involves chromatin condensation and nuclear elongation, with visible cytoplasmic elimination. At this stage, a large amount of microtubules and glycogen can also be seen in Sertoli cell cytoplasm, surrounding each spermatid. The spermatozoon is fusiform and the acrossome forms a cap in the anterior region of the nucleus. A mitochondrial sleeve is found around the proximal portion of the tail. The tail presents an axonema with a 9+2 pattern, a justaxonemal fiber, an undulating membrane, and the absence of axial rod. This organization shows some similarities with species of the genus Physalaemus (Leiuperidae) such as P. biligonigerus (Cope, 1861), P. gracilis (Boulenger, 1883) and P. fuscomaculatus (Steindachner, 1864).
\end{abstract}

KEYWORDS. Anura, Eupemphix nattereri, ultrastructure, spermiogenesis, spermatozoon.

RESUMO. A maturação dos espermatozóides envolve um extenso e complexo processo que começa com a proliferação e diferenciação das espermatogônias, passa pela meiose e finaliza com a espermiogênese. Nessa fase, eventos envolvendo alterações morfológicas e bioquímicas transformam espermátides em espermatozóides. Aspectos ultra-estruturais da espermiogênese e do espermatozóide do anuro Eupemphix nattereri (Steindachner, 1863) foram analisados através de microscopia eletrônica de transmissão. A espermiogênese envolve condensação da cromatina e alongamento nuclear, com visível eliminação de citoplasma. Nesse estágio, grande quantidade de microtúbulos e glicogênio podem ser visualizados no citoplasma das células de Sertoli, rodeando cada espermátide. O espermatozóide é fusiforme e o acrossomo forma uma capa na região anterior do núcleo. A bainha mitocondrial é encontrada ao redor da porção proximal da cauda. A cauda apresenta o axonema com o modelo 9+2, uma fibra axonemal, a membrana ondulante e ausência de bastão axial. Esta organização apresenta algumas similaridades com espécies do gênero Physalaemus (Leiuperidae) como P. biligonigerus (Cope, 1861), P. gracilis (Boulenger, 1883) e P. fuscomaculatus (Steindachner, 1864).

PALAVRAS-CHAVE. Anura, Eupemphix nattereri, ultra-estrutura, espermiogênese, espermatozóide.

Os espermatozóides dos anfíbios são geralmente células alongadas e especialmente modificadas para nadar. A morfologia básica dos espermatozóides dos anfíbios consiste de: cabeça (contendo capa acrossomal e núcleo) e cauda com peça intermediária e principal (DUELLMAN \& Trueb, 1994). A formação desses gametas envolve um extenso e complexo processo que se inicia com a proliferação e diferenciação das espermatogônias, passa pela meiose e termina com a espermiogênese (RASTOGI et al., 1988). Este último evento envolve alterações morfológicas e bioquímicas que transformam espermátides em espermatozóides (PHILIPS, 1974).

A gametogênese e a morfologia do espermatozóide de alguns anuros têm sido estudadas em condições particulares de fertilização, por meio de observações baseadas na morfologia e motilidade in vitro (WAGGENER \& CARrol, 1998). A grande variação morfológica e morfométrica na estrutura do acrossomo, perfuratorium e filamento caudal tem contribuído também para a caracterização taxonômica e filogenética (FouQuETTE \& Delahoussaye, 1977; Garrido et al., 1989; Lee \& JAMIESON, 1992, 1993; JAMIESON et al., 1993; KwON \& LeE,
1995; Meyer et al., 1997; JAMIESON \& Scheltinga, 1997; Scheltinga et al., 2002).

Aspectos morfológicos e funcionais da espermiogênese têm sido descritos em vários estudos com anuros, especialmente no que concerne aos complexos eventos envolvendo formação do acrossomo (Sprando \& Russell, 1988; Rastogi et al., 1988), compactação cromatínica, alongamento nuclear (REED \& Stanley, 1972; Cavicchia \& Moviglia, 1983; Báo et al., 1991; LeE \& JAMieson, 1992, 1993; LeE \& Kwon, 1992; TABOGA \& Dolder, 1998) e formação do flagelo (TABOGA \& DOLDER, 1993).

São poucos os trabalhos baseados em questões da biologia reprodutiva para os gêneros que compõem a família Leiuperidae como as contribuições para algumas espécies do gênero Physalaemus (Fitzinger, 1826) (RYAN et al., 1983; RyAn, 1990; BARRETO \& ANDRADE, 1995; Wogel et al., 2002) e do gênero Eupemphix (Steindachner, 1863) (OliveIRA \& ZiERI, 2005). Alguns destes estudos se referem aos aspectos morfológicos do aparelho reprodutor masculino de Physalaemus cuvieri (Fitzinger, 1826) (Oliveira et al., 2002, 2003b) e à caracterização 
estrutural de espermatozóides de P. biligonigerus (Cope, 1861), P. fuscomaculatus (Steindachner, 1864) e P. centralis (Bokermann, 1962) (AMARAL et al., 1999). Este trabalho descreve modificações ultra-estruturais que ocorrem durante a espermiogênese bem como a ultra-estrutura do espermatozóide do anuro Eupemphix nattereri (Steindachner, 1863) visando contribuir com dados morfológicos que possibilitem estudos comparativos entre espécies dessa família, bem como para a ampliação do conhecimento da biologia reprodutiva de anuros neotropicais.

\section{MATERIAL E MÉTODOS}

Foram utilizados dez machos adultos de Eupemphix nattereri, coletados em lagoas temporárias

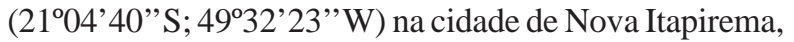
distrito de Nova Aliança, Estado de São Paulo, Brasil. As coletas foram realizadas no início da estação chuvosa entre os meses de setembro e outubro de 2003. Os espécimes foram fixados e incorporados à coleção Herpetológica do Departamento de Zoologia e Botânica do IBILCE, UNESP-SJRP (Lote 640-D; numerados de 8380 a 8389).

Os espécimes foram anestesiados com éter etílico e tiveram suas gônadas removidas após incisão mediana ventral. Para as observações na microscopia eletrônica, as amostras foram fixadas por $2 \mathrm{~h} \mathrm{a} 25^{\circ} \mathrm{C} \mathrm{em}$ solução de glutaraldeído 3\% e ácido tânico $0,25 \%$ em tampão Millonig ( $\mathrm{pH} 7,3$ e $0,2 \mathrm{M}$ ), e lavados posteriormente no mesmo tampão. Os fragmentos foram pós-fixados em solução de tetróxido de ósmio a $1 \%$ por 1 hora, lavados brevemente em solução tamponada, desidratados em acetona e incluídos em araldite (CotTa-Pereira et al., 1976).

Secções ultrafinas foram contrastadas pelo acetato de uranila a 2\%, durante 20 minutos (WATSON, 1958) e pelo citrato de chumbo a $2 \%$ em solução $1 \mathrm{~N}$ de hidróxido de sódio (Venable \& Coggeshall, 1965), durante 8 minutos, e analisadas em microscópio eletrônico de transmissão.

\section{RESULTADOS}

No início da diferenciação as espermátides apresentam o núcleo arredondado, bastante pronunciado e a cromatina com aspecto frouxo. No citoplasma identificam-se organelas como mitocôndrias, complexo de Golgi, centríolos e retículo endoplasmático liso (Fig. 1). No transcorrer da fase inicial, vesículas originadas pelo complexo de Golgi se fundem formando o acrossomo (Fig. 2) e o centríolo distal origina o filamento caudal (Figs. 3 e 4).

Os estádios intermediários são caracterizados pela compactação da cromatina e alongamento nuclear, e no citoplasma estão presentes retículo endoplasmático liso, mitocôndrias e fragmentos do envoltório nuclear denominados lamelas aneladas (Fig. 5), além de material vacuolizado sob a forma de vesículas (Figs. 6 e 7). No citoplasma da célula de Sertoli, envolvendo cada espermátide, pode-se observar grande quantidade de microtúbulos de arranjo helicoidal e paralelos ao sentido do alongamento nuclear, bem como uma grande quantidade de grânulos de glicogênio (Figs. 8 e 9). Concomitantemente ao alongamento do núcleo, o citoplasma das espermátides se deslocam e se desprendem, reduzindo assim o material citoplasmático da região nuclear (Figs. 5-7). A cromatina apresenta-se com pequenos grumos uniformemente distribuídos (Figs. 7-9), até atingir um alto grau de compactação, verificado pela conspícua eletrodensidade nuclear e quase ausência de material citoplasmático (Fig. 10).

Em estádio já avançado da citodiferenciação, as espermátides tardias que anteriormente estavam envolvidas inteiramente pelo citoplasma da célula de Sertoli formando agrupamentos de células ou cistos espermatogenéticos, estão agora organizadas em feixes paralelos, com apenas a porção anterior mergulhada e fixa no citoplasma da célula de Sertoli. A célula de Sertoli apresenta núcleo bem evidente com a cromatina finamente distribuída, ao redor dos quais se distribuem várias mitocôndrias (Fig. 11).

As espermátides tardias e os espermatozóides apresentam três partes principais distintas: cabeça, peça intermediária e cauda. Revestindo a porção anterior do núcleo, como uma capa, está a vesícula acrossômica alongada e cônica; logo abaixo encontrase o perfuratorium, estrutura cônica, alongada, fibrilar e eletrodensa; e anteriormente ao núcleo identifica-se o espaço subacrossomal. Estas três estruturas formam o complexo acrossômico (Fig. 12). O núcleo, bastante compacto e alongado possui cromatina condensada, e em sua região posterior, uma pequena quantidade de material citoplasmático contendo mitocôndrias (Fig. 13).

A peça intermediária apresenta dois centríolos perpendiculares embebidos no material pericentriolar, o centríolo proximal, localizado mais próximo ao núcleo (Fig. 13), e o centríolo distal, responsável pelo desenvolvimento do flagelo. A estrutura flagelar pode ser ultra-estruturalmente subdividida em três regiões: estrias transversais, centríolo distal e axonema (Fig. 4). Uma bainha citoplasmática, contendo mitocôndrias e lamelas aneladas, envolve o axonema e a fibra justaxonemal na porção inicial do flagelo, ainda na peça intermediária (Fig. 14), e se torna delgada (Fig. 15) até desaparecer completamente.

A cauda consiste de um axonema, constituído pelo arranjo convencional de microtúbulos $(9+2)$, uma fibra justaxonemal e na região mediana da cauda também se encontra uma extensa membrana ondulante (Fig. 16). O axonema e a fibra justaxonemal são rodeados por uma membrana citoplasmática comum e à medida que vão se aproximando da região terminal da cauda ocorre uma redução da fibra justaxonemal e ausência da membrana ondulante (Fig.17). 

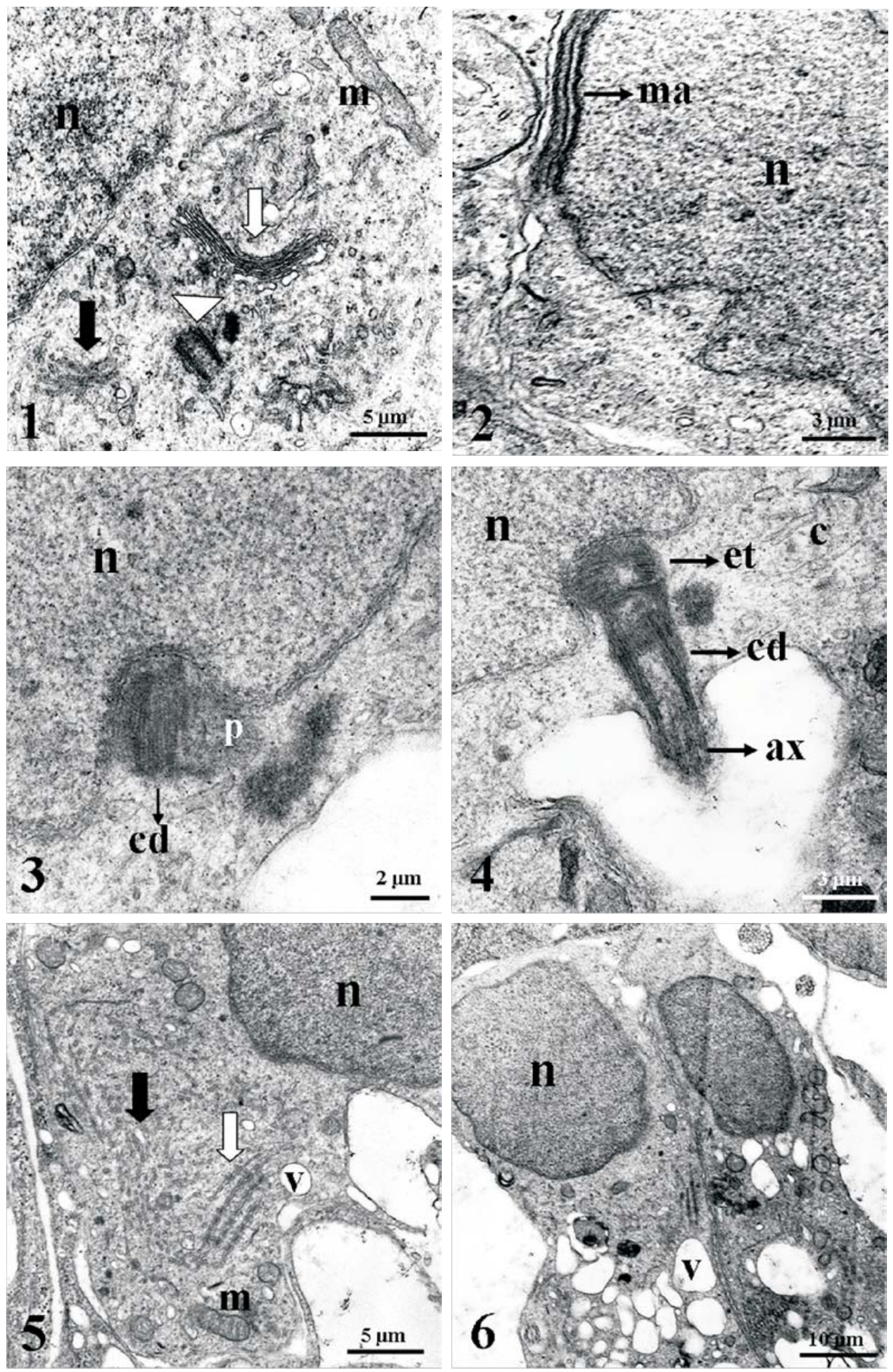

Figs. 1-6. Espermiogênese em Eupemphix nattereri (Steindachner, 1863). 1, Espermátide inicial com um desenvolvido complexo de Golgi (seta clara), que dará origem à membrana acrossômica, um dos centríolos do par (cabeça de seta), mitocôndria (m), retículo endoplasmático liso (seta escura) e núcleo com a cromatina dispersa (n); 2, Corte sagital em espermátide inicial mostrando a membrana acrossômica (ma) associada à porção anterior do núcleo (n); 3, Secção longitudinal de espermátide em fase inicial do desenvolvimento do flagelo, mostrando o núcleo (n) com a cromatina dispersa, o centríolo distal (cd) situado na fossa nuclear e a presença de material pericentriolar (p); 4, Seccão longitudinal de espermátide, evidenciando a orientação perpendicular do centríolo distal com a membrana plasmática, a presença de microtúbulos no axonema em formação na futura região da peça intermediária. Axonema (ax), centríolo distal (cd), citoplasma (c), estriações transversais (et) e núcleo (n); 5-6, Espemátides com núcleo (n) ovóide e resíduo citoplasmático volumoso contendo mitocôndrias (m), lamelas aneladas (seta clara), retículo endoplasmático liso (seta escura) e vesículas (v) eliminando porções citoplasmáticas. 


\section{DISCUSSÃO}

O processo espermatogenético em $E$. nattereri ocorre em estruturas denominadas lóculos seminíferos, nos quais o epitélio germinativo é organizado em espermatocistos, de maneira similar ao descrito para outros anuros (Hermosilla et al., 1983; RAstogi et al., 1988; OliveIra et al., 2002; OliveIRA et al., 2003a,b). Na medida em que se formam as espermátides alongadas, $\mathrm{o}$ arranjo cístico se desfaz e então estas células se agrupam em feixes compactos (SPRANDo \& Russel, 1988; Oliveira et al., 2003a).

Como verificado por Oliveira et al. (2003a) em Scinax fuscovarius (Lutz, 1925) e por TABOGA \& DOLDER (1991) em Scinax ranki (= Hyla ranki) (Andrade \& Cardoso, 1987), as espermátides de E. nattereri também sofrem um processo de diferenciação que envolve várias alterações núcleo-citoplamáticas: alongamento nuclear, condensação do material cromatínico, formação do acrossomo, desenvolvimento da cauda e perda do material citoplasmático.

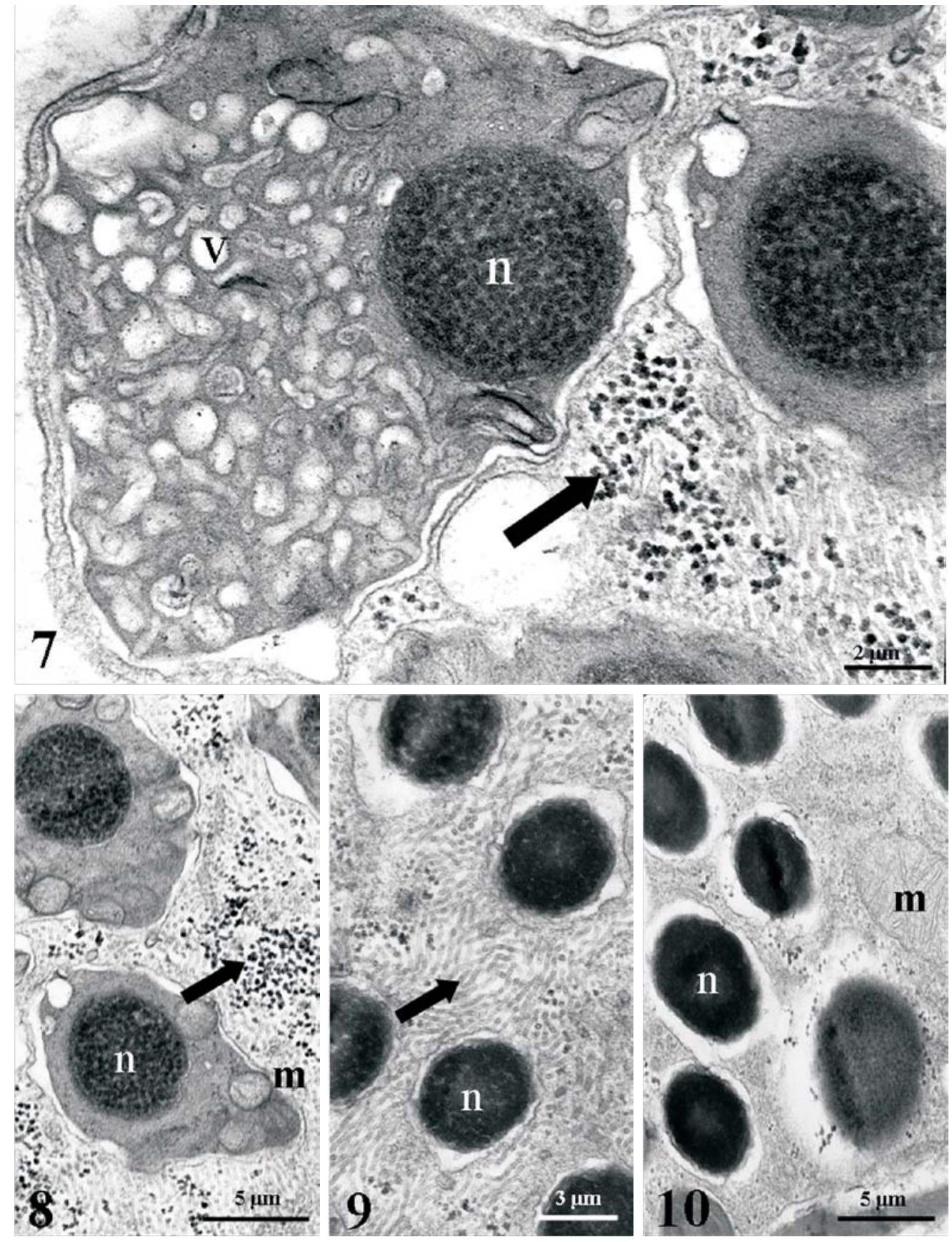

Figs. 7-10. Espermiogênese em Eupemphix nattereri (Steindachner, 1863). 7-8, Espermátides em secção transversal com o padrão de compactação da cromatina em grumos densos (n), citoplasma com grande quantidade de mitocôndrias (m) e de vesículas citoplasmáticas (v) contendo material a ser eliminado. O citoplasma da célula de Sertoli está repleto de grânulos de glicogênio (seta); 9, Espermátides em secção transversal mostrando o núcleo (n) e citoplasma da célula de Sertoli repleto de microtúbulos (seta); 10, Célula de Sertoli contendo mitocôndria $(\mathrm{m})$, secção transversal com adiantado grau de compactação nuclear (n). 
O núcleo das espermátides de E. nattereri sofre gradual condensação e aumento de eletrodensidade, como descrito para Megophrys montana (Kuhl \& Hasselt, 1822) (Asa \& Phillips, 1988) e para P. biligonigerus, $P$. fuscomaculatus e $P$. gracilis (Boulenger, 1883) (AMARAL et al., 1999). O processo de alongamento celular é auxiliado por uma grande quantidade de microtúbulos no citoplasma da célula de Sertoli que entremeia as espermátides e uma menor quantidade na região perinucleolar (RASTOGi et al., 1988; BÁo et al., 1991; AMARAL et al., 1999).
Além dos microtúbulos que atuam no alongamento das espermátides, também se observa no citoplasma da célula de Sertoli de E. nattereri uma grande quantidade de grânulos de glicogênio, como observado em Rana catesbeiana (Shaw, 1802) (SPRANDo \& RusSEL, 1988) e Pachymedusa dacnicolor (Cope, 1864) (RASTOGI et al., 1988).

Outra característica das espermátides de $E$. nattereri é a grande redução do volume citoplasmático, através da perda de prolongamentos sob a forma de vesículas, que serão fusionadas e reabsorvidas pelas
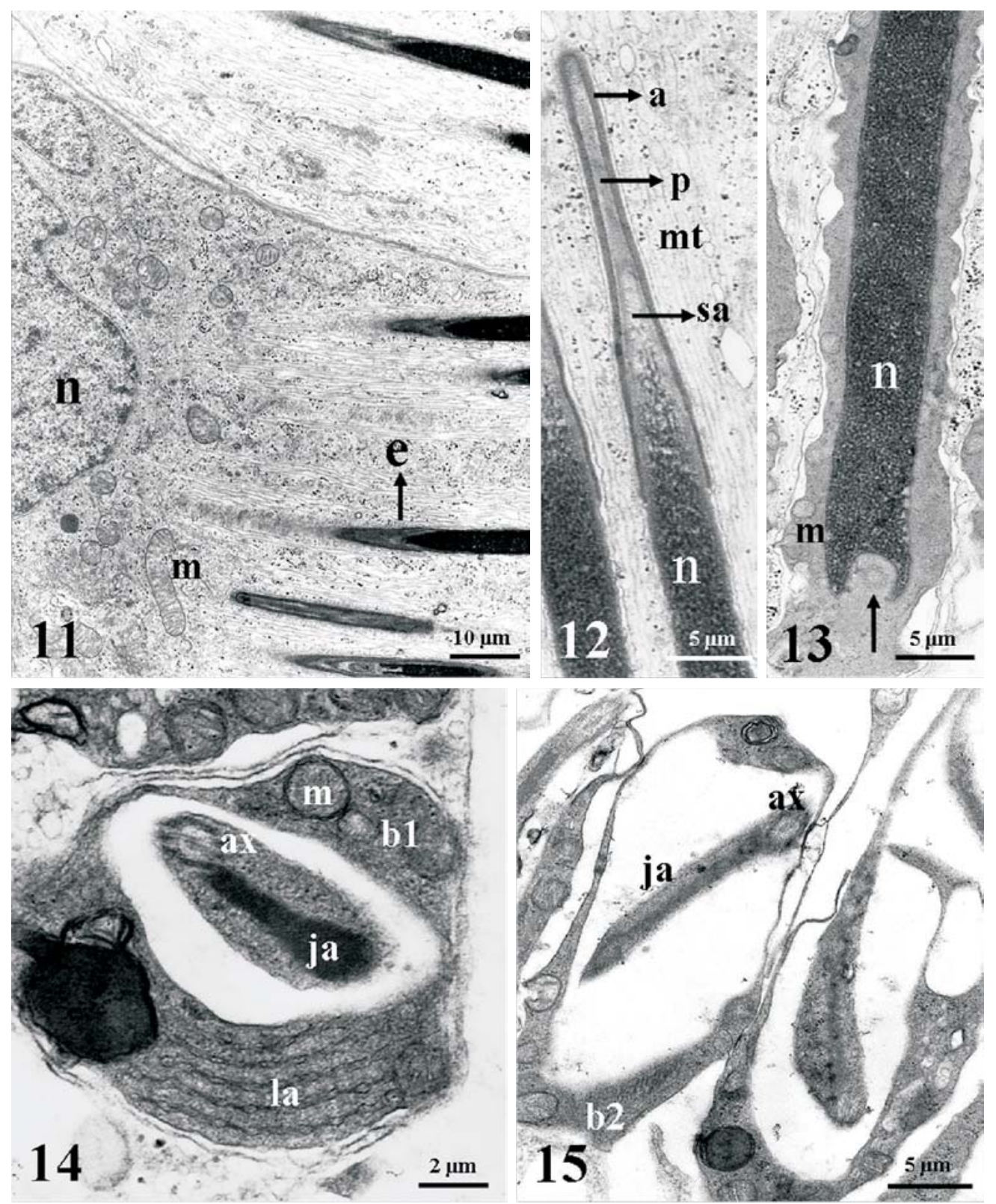

Figs. 11-15. Espermiogênese em Eupemphix nattereri (Steindachner, 1863). 11, Secção longitudinal em feixe de espermátides tardias (e) no interior da célula de Sertoli. A célula de Sertoli apresenta núcleo (n) com cromatina frouxa e no citoplasma observa-se mitocôndrias (m), inúmeros microtúbulos e grânulos de glicogênio ao redor das espermátides; 12, Secção longitudinal de espermátide tardia entremeada pelo citoplasma da célula de Sertoli. Acrossomo (a), perfuratorium (p), espaço subacrossomal (sa), núcleo (n) e microtúbulos (mt) rodeando a espermátide; 13, Secção longitudinal de espermátide tardia. Núcleo (n), mitocôndria (m) e centríolo proximal (seta); 14-15, Secção transversal em diferentes alturas na região proximal da cauda, envolta pela bainha citoplasmática. Quanto mais próxima da peça intermediária, a bainha é mais espessa (b1), contendo mitocôndria (m) e lamelas aneladas (la). À medida que se distancia desta porção, a bainha (b2) torna-se mais delgada. O filamento caudal está representado pelo axonema (ax) e pela fibra justaxonemal (ja). 

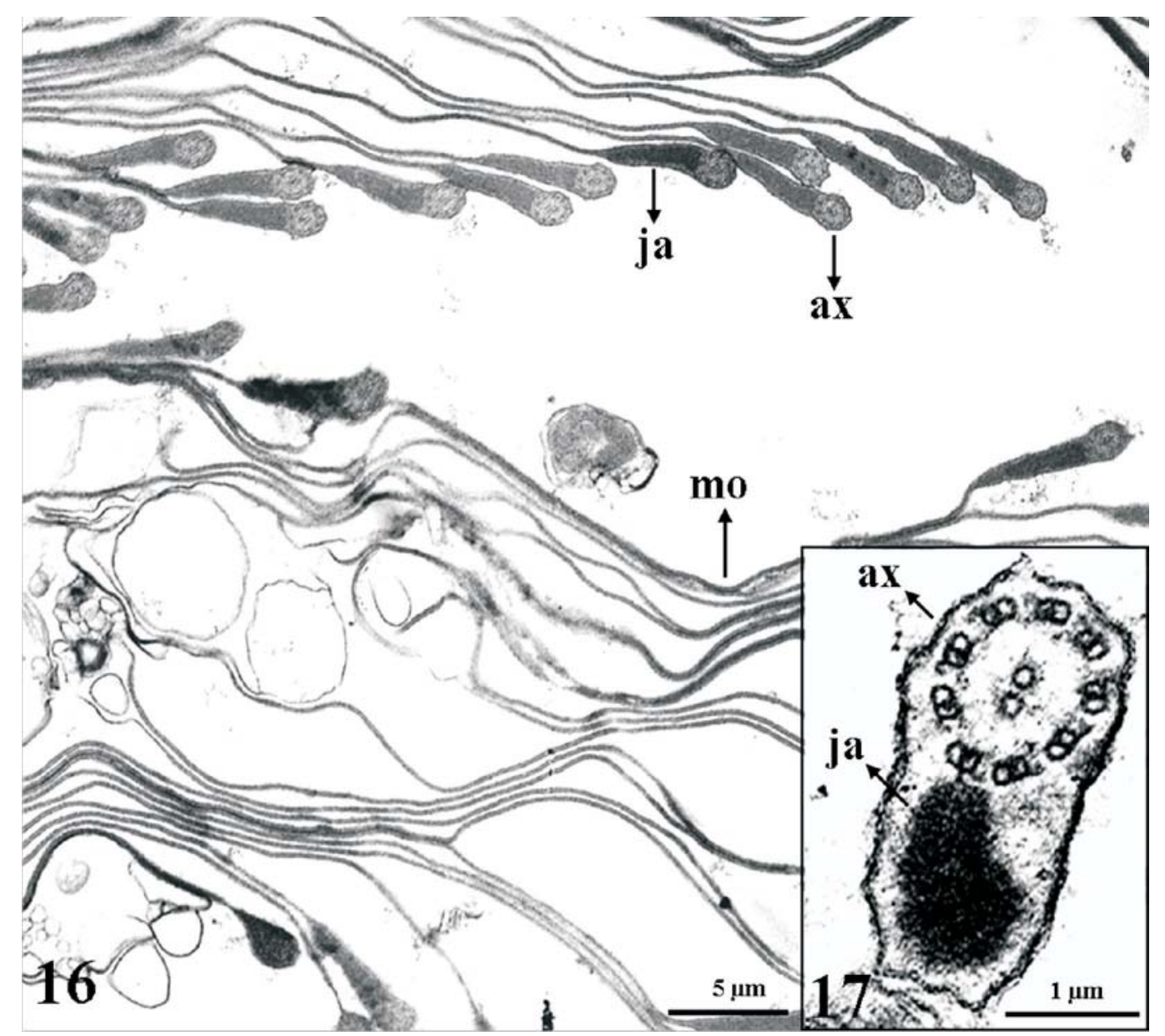

Figs. 16-17. Espermiogênese em Eupemphix nattereri (Steindachner, 1863). 16, Secção transversal da porção mediana da cauda. Axonema (ax), fibra justaxonemal (ja) e membrana ondulante (mo); 17, Secção transversal da porção final da cauda. Axonema (ax) e fibra justaxonemal (ja).

células de Sertoli como em H. ranki (TABOGA \& DolDER, 1998) ou degradadas no epitélio do ducto de Wolff como em $R$. catesbeiana (SPRANDO \& Russel, 1988).

Nas etapas finais da espermiogênese, o acrossomo apresenta uma capa de forma cônica na região anterior do núcleo como em outros anfíbios (NICANDER, 1970; RASTOGI et al., 1988; BÁo et al., 1991; AMARAL et al., 1999) e o perfuratorium localizado entre o acrossomo e o núcleo. Esta estrutura contém fillamentos de actina e desempenha papel importante durante a penetração no óvulo (BACCETI et al., 1980).

Entre os vertebrados, os anfíbios apresentam uma enorme diversidade em suas estratégias reprodutivas e locais de fertilização (DuEllman \& Trueb, 1994), isso reflete em uma grande diferenciação e variabilidade no filamento caudal, tendo em vista os anexos protéicos e peças membranosas que esta região pode apresentar em gametas de diferentes anfíbios já estudados (TABOGA \& DOLDER, 1993). Em E. nattereri, além de mitocôndrias localizadas e comumente descritas na bainha citoplasmática, uma peculiaridade em espermátides tardias é a persistência de lamelas aneladas na bainha citoplasmática.

O filamento caudal apresenta um axonema típico $(9+2)$ sem nenhum anexo caudal em $R$. pipiens (Screber,
1782) e $R$. clamitans (Latreille, 1801) (POIRIER \& SPINK, 1971) e alguns Microhilídeos (Scheltinga et al., 2002), ou com dois axonemas em Megophrys montana (Kuhl \& van Hasselt, 1822) (Asa \& Phillips, 1988) e Lepdobatrachus laevis (Budgett, 1899) (WAGGENER \& CARrol JR., 1998). O filamento caudal com axonema, membrana ondulante e bastão axial está presente em Pachymedusa dacnicolor (RAstogi et al., 1988) e Bufo gargarizans Cantor, 1842 (Kwon \& LeE, 1995). A cauda de Hyla japonica (Günther, 1859) consiste de um axonema e um bastão axial, mas não possui uma membrana ondulante (Kwon \& LEE, 1995). O anuro E. nattereri possui o filamento caudal constituído por axonema, membrana ondulante, fibra justaxonemal e ausência do bastão axial, semelhante ao descrito por AMARAL et al. (1999) para três espécies de Physalaemus.

A descrição do gameta de E. nattereri confere características morfológicas que reforçam a proximidade filogenética com outras espécies da família Leiuperidae.

Agradecimentos. A FAPESP pelo auxílio à pesquisa (processos $n^{\circ}$. 2002/08016-9 e 2005/02919-5). A CAPES pela concessão da bolsa de Mestrado para Rodrigo Zieri. 


\section{REFERÊNCIAS BIBLIOGRÁFICAS}

Amaral, M. J. L. V.; Fernandes, A. P.; Báo, S. N. \& Recco-Pimentel, S. M. 1999. An ultrastructural study of spermiogenesis in three species of Physalaemus (Anura, Leptodactylidae). Biocell 23(3):211-221.

AsA, C. S. \& Phillips, D. M. 1988. Nuclear shaping in spermatids of the Thai leaf frog Megophrys montana. Anatomical Record 220(3):287-290.

Baccetti, B.; Bigliardi, E. \& Burrini, A. G. 1980. The morphogenesis of the vertebrate perfuratorim. Journal of Ultrastructure Research 71:272-287.

Báo, S. N.; Dalton, G. C. \& Oliveira, S. F. 1991. Spermiogesis in Odontophrynus cultripes (Amphibia, Anura, Leptodactylidae): ultrastructural and cytochemical studies of proteins using EPTA. Journal of Morphology 207(3):303-314.

Barreto, L. \& Andrade, G. V. 1995. Aspects of the reproductive biology of Physalaemus cuvieri (Anura: Leptodactylidae) in northeastern Brazil. Amphibia-Reptilia 16:67-76.

Cavicchia, J. C. \& Moviglia, G. A. 1983. The blood-testis barrier in the toad (Bufo arenarum, Hensel): a freeze-fracture and lanthanum tracer study. Anatomical Record 205(4):387-396.

Cotta-Pereira, G.; Rodrigo, F. G. \& David-Ferreira, J. F. 1976. Use of tannic acid-glutaraldehyde in study of elastic and elastic-related fibers. Stain Technology 51(1):7-11.

Duellman, W. E. \& Trueb, L. 1994. Biolology of Amphibia. New York, McGraw-Hill Book Company. 670p.

Fouquette JR., M. J. \& Delahoussaye, A. J. 1977. Sperm morphology in the Hyla rubra (Amphibia, Anura, Hylidae), and its bearing on generic status. Journal of Herpetology 11(4):387-396.

Garrido, O.; Pugin, E. \& Jorquera, B. 1989. Sperm morphology of Batrachyla (Anura: Leptodactylidae). Amphibia-Reptilia 10:141-149.

Hermosilla, I. B.; Urbina, A. P. \& Cabrera, J. C. P. 1983. Espermatogenesis en la rana Chilena Caudiverbera caudiverbera (Linneu, 1758) (Anura, Leptodactylidae). Boletin de la Sociedad de Biologia de Concepción 54:103-115.

Jamieson, B. G. M. \& Scheltinga, D. M. 1997. Sperm ultrastructure of six Australian hylid frogs from two genera (Litoria and Cyclorana): phylogenetic implications. Journal of Submicroscopic Cytology and Pathology 29(4):443-451.

Jamieson, B. G. M.; LeE, M. S. Y. \& LonG, K. 1993. Ultrastructure of the spermatozoon of the internally fertilizing frog Ascaphus truei (Ascaphidae: Anura: Amphibia) with phylogenetic applications. Herpetologica 49:52-65.

Kwon, A. S. \& LeE, Y. H. 1995. Comparative spermatology of anurans with special references to phylogeny. In: Advances in Spermatozoal Phylogeny and Taxonomy. Memoires du Museum National d'Histoire Naturelle 166:321-332.

LeE, M. S. Y. \& Jamieson, B. G. M. 1992. The ultrastructure of the spermatozoa of three species of Myobatrachid frogs (Anura, Amphibia) with phylogenetic considerations. Acta Zoologica 73:213-222.

1993. The ultrastructure of the spermatozoa of bufonid and hylid frogs (Anura, Amphibia): implications for phylogeny and fertilization biology. Zoologica Scripta 22(3):309-323

LeE, M. S. Y. \& Kwon, A. S. 1992. Ultrastructure of spermiogenesis in Hyla japonica (Anura, Amphibia). Acta Zoologica 73:49-55.

Meyer, E.; Jamieson, B. G. M. \& Scheltinga, D. M. 1997. Sperm ultrastructure of six Australian hylid frogs from two genera (Litoria and Cyclorama) phylogenetic implications. Journal of Submicroscopic Cytology and Pathology 29:433-451.

NiCANDER, L. 1970. Comparative studies on the fine structure of vertebrate spermatozoa. In: B ACCETTI, B. ed. Comparative
Spermatology. New York, Academic. p.47-62.

Oliveira, C. \& Zieri, R. 2005. Pigmentação testicular em Physalaemus nattereri (Steindachner) (Amphibia, Anura) com observações anatômicas sobre o sistema pigmentar extracutâneo. Revista Brasileira de Zoologia 22(2):454-460.

Oliveira, C.; Vicentini, C. A. \& Taboga, S. R. 2003a. Structural characterization of nuclear phenotypes during Scinax fuscovarius spermatogenesis (Anura, Hylidae). Caryologia 56(1):75-83.

Oliveira, C.; Zanetoni, C. \& Zieri, R. 2002. Morphological observations on the testes of Physalaemus cuvieri (Amphibia, Anura). Revista Chilena de Anatomia 20(3):263-268.

Oliveira, C.; Sant'anna, A. C.; Omena, P. M.; Santos, L. R. S. \& Zieri, R. 2003b. Morphological considerations on the seminiferous structures and testes of anuran amphibians: Bufo crucifer, Physalaemus cuvieri and Scinax fuscovarius. Biociências 11(1):39-46.

Phlllips, D. M. 1974. Spermiogenesis. New York \& London, Academic. p.1-68.

PoIrIER, G. R. \& SPINK, G. E. 1971. Ultrastructure of testicular spermatozoa in two species of Rana. Journal of Ultrastructure Research 36:455-465.

Rastogi, R. K.; Bagnara, J. T.; Iela, L. \& Krasovich M. A. 1988. Reproduction in the Mexican leaf frog, Pachymedusa dacnicolor. IV. Spermatogenesis: a light and ultrasonic study. Journal of Morphology 197(3):277-302.

Reed, S. C. \& Stanley, H. P. 1972. Fine structure of spermatogenesis in the South African clawed toad Xenopus laevis Daudin. Journal of Ultrastructure Research 41:277-295.

Ryan, M. J. 1990. Vocal morphology of the Physalaemus pustulosus species group (Leptodactilydae): morphological response to sexual selection for complex calls. Biological Journal of the Linnean Society 40:37-52.

Ryan, M. J.; Bartholomeu, G. A. \& Rand, A. S. 1983. Energetics of reproduction in a Neotropical frog, Physalaemus pustulosus. Ecology 64(6): 1457-1462.

Scheltinga, D. M.; Jamieson, B. G. M.; Bickford, D. P.; Garda, A. A.; Báo, S. N. \& Mcdonald, K. R. 2002. Morphology of the spermatozoa of the Microhylidae (Anura, Amphibia). Acta Zoologica 83:263-275.

Sprando, R. L. \& Russel, L. D. 1988. Spermiogenesis in the bull frog (Rana catesbeiana): a study of cytoplasmic events including cell volume changes and cytoplasmic elimination. Journal of Morphology 198:303-319.

Taboga, S. R. \& Dolder. A. M. H. 1991. Análise histológica da espermatogênese de Hyla ranki (Amphibia, Anura, Hylidae). Revista Brasileira de Ciências Morfológicas 2:66-71. 1993. Ultrastructural analysis of the Hyla ranki spermatozoan tail (Amphibia, Anura, Hylidae). Cytobios 75:85-92. 1998. Spermiogenesis of Scinax ranki (Amphibia, Anura, Hylidae): nuclear compactation and associated cytoplasmic events. Brazilian Journal of Morphological Science 15:157-163.

Venable, J. H. \& Coggeshall, R. 1965. A simplified lead citrate stain for use in electron microscopy. Journal of Cell Biology 25:407-408.

Waggener, W. L. \& CARrol JR., E. J. 1998. Spermatozoon structure and motility in the anuran Lepidobatrachus laevis. Development, Growth and Differentiation 40:27-34.

WAtson, M. L. 1958. Staining of tissue sections for electron microscopy with heavy metals. Journal of Biophysical and Biochemical Cytology 4:475-478.

Wogel, H.; Abrunhosa, P. A \& Pombal JR., J. P. 2002. Atividade reprodutiva de Physalaemus signifer (Anura, Leptodactylidae) em ambiente temporário. Iheringia, Série Zoologia, 92(2):57-70.

Recebido em junho de 2005. Aceito em outubro de 2007. ISSN 0073-4721

Artigo disponível em: www.scielo.br/isz 